\title{
Que aritmética para ensinar sistema métrico deci- mal? Saberes profissionais para o seu ensino
}

\author{
Marcos Denilson Guimarães \\ Universidade Federal do Maranhão \\ Martha Raíssa lane Santana da Silva \\ Universidade Federal de São Paulo \\ Denise Medina França
}

Universidade do Estado do Rio de Janeiro (Brasil)

\section{Resumo}

marco legal de implantação do Sistema Métrico Decimal (SMD) nas escolas brasileiras pela Lei Imperial de 1862, Lei n 1 157, de 26 de junho, promulgada por D. Pedro II, completaria hoje seus 158 anos. Neste estudo, de natureza sócio-histórica, foram problematizados os processos de escolarização do saber SMD, levando também em consideração tópicos referentes à formação didático-metodológica de professores que ensinam matemática. Com o objetivo de caracterizar a abordagem de um Sistema Métrico Decimal a ensinar e para ensinar, foram analisados trabalhos publicados por pesquisadores entre os anos de 2007 a 2018 que abordavam esse saber em manuais escolares. Conclui-se que a matemática a e para ensinar o SMD sofreu transformações em termos de ordenação do saber, bem como modificações no programa com progressiva inserção desse conteúdo, em substituição ao antigo Sistema de Pesos e Medidas. Ao longo do período observa-se uma caracterização de um SMD intuitivo prático.

Palavras-chave: Aritmética. História da educação matemática. Sistema métrico decimal. Saberes profissionais.

\section{What arithmetic to teach decimal metric system? Professional knowledge for your teaching}

\begin{abstract}
The legal framework for the implementation of the Decimal Metric System (DMS) in Brazilian schools by the Imperial Law of 1862, Law No. 1 157, of June 26, promulgated by D. Pedro II, would now complete its 158 years. In the present study, from a socio-historical nature, the processes of schooling DMS, knowledge were problematized, also taking into account topics related to the didactic-methodological training of teachers who teach mathematics. In order to characterize the approach of a Decimal Metric System to be taught and for teach, studies published by researchers between the years 2007 to 2018 that addressed DMS from school textbooks were analyzed. It is concluded that the mathematics to teach and for teach the DMS underwent transformations in terms of ordering knowledge, as well as modifications in the program with progressive insertion of this content, replacing the old System of Weights and Measures. Throughout the period there is a characterization of a practical intuitive DMS.
\end{abstract}


Keywords: Arithmetic. History of mathematics education. Decimal metric system. Professional knowledge.

\section{¿Qué aritmética para enseñar sistema métrico decimal? Conocimientos profesionales para su docencia}

\section{Resumen}

El marco legal para la implantación del Sistema Métrico Decimal (SMD) en las escuelas brasileñas por la Ley Imperial de 1862, Ley n 1 157, de 26 de junio, promulgada por D. Pedro II, compliría hoy sus 158 años. En este estúdio, de carácter sócio-histórico, se han problematizado los procesos de escolarización del conocimiento del SMD, teniendo en cuenta también temas relacionados a la formación didáctico-metodológica de los profesores que enseñan matemáticas. Con el objetivo de caracterizar el abordaje de un Sistema Métrico Decimal a enseñar y para enseñar, han sido analizados estudios publicados por investigadores entre los años 2007 hasta 2018 que abordaban el SMD en manuales escolares. Se concluye que la matemática a y para enseñar el SMD ha sufrido cambios en cuanto al ordenamiento del saber, así como modificaciones en el programa con inserción progresiva de esse contenido, en sustitución del antiguo Sistema de Pesos y Medidas. A lo largo del periodo se puede ver uma caracterización de un SMD intuitivo práctico.

Palabras claves: Aritmética. Historia de la educación matemática. Sistema métrico decimal. Conocimientos profesionales.

\section{Introdução}

Começamos este artigo a partir da seguinte questão: é possível caracterizar uma Aritmética para ensinar a partir dos registros deixados por manuais escolares no período de padronização e escolarização do Sistema de Pesos e Medidas no Brasil (1832 a 1923), face ao movimento de passagem da Pedagogia Tradicional para a Pedagogia Moderna?

Ao tentar responder a essa questão, cabe-nos, de pronto, mencionar que nossa investigação se deu a partir de trabalhos já produzidos por pesquisadores vinculados ao Grupo de Pesquisa de História da Educação Matemática do Brasil (GHEMAT/Brasil), durante os anos de 2007 a 2018 . O período delimitado, bem como a ênfase nos estudos de um grupo específico, se justifica por dois motivos: o primeiro, pelo nosso pertencimento ao Grupo e, segundo, pelo volume de produções acumuladas com o desenvolvimento de projetos coletivos de pesquisa ${ }^{1}$. 
Além de um trabalho de revisão bibliográfica, este trabalho possui uma natureza sócio-histórica, que nos dá referências para caracterizar saber a e para ensinar, filiando-se também à perspectiva histórico-cultural ICHARTIER, 1990) como forma de interpretação das diferentes representações que podem ser lidas na tentativa de compreender a constituição de um saber em vias de objetivação, o SMD.

Nesse sentido, acreditamos que os estudos, originários dos referidos projetos, expressam as representações e as apropriações dos autores acerca da história da aritmética na escola primária brasileira, matéria escolar que durante a existência dos grupos escolares, período de quase um século 1890 a 1970), ocupou um lugar de destaque na programação desta instituição no Brasil (SOUZA, 2009; VIDAL, 2006).

Outro fato que merece atenção é a ideia de caracterização de uma Aritmética para ensinar, como vem sendo proposto desde o título deste trabatho. Nesse caso, o nosso referencial teórico-metodológico advém dos estudos de origem suíça que mobilizam categorias de análise como "[...] saberes profissionais, saberes objetivados, sistematização dos saberes e sua institucionalização" (VALENTE; BERTINI; PINTO; MORAIS, 2017, p. 9). $\bigcirc$ entendimento desses termos será mais bem explicitado ao longo deste texto.

Para Valente (2019, p. 18), cabe a nós, historiadores da educação matemática, realizarmos a seguinte tarefa: "[...] caracterizar essas matemáticas e mostrar como elas estão relacionadas". Diante disso, voltamos a formular a seguinte questão, agora de modo um tanto mais cirúrgico: Que elementos do saber profissional do professor dos anos iniciais podem ser caracterizados como uma aritmética para ensinar, nos trabalhos do GHEMAT, a partir da padronização e escolarização do saber Sistema de Pesos e Medidas no Brasil? A seguir, justificamos a escolha por este conteúdo.

\section{Como analisar historicamente os processos de produção de saberes docentes?}

tema referente aos processos de constituição dos saberes da base profissional dos professores sobre saberes matemáticos é objeto de estudo do GHEMAT, no qual se busca problematizar o movimento de produção e transformação de saberes ligados à profissão docente. Numa perspectiva histórica, 
analisa a elaboração de processos para a constituição de uma matemática a ensinar e de uma matemática para ensinar, e as dinâmicas de articulação desses saberes.

Partindo da apropriação dos conceitos de saberes a ensinar e saberes para ensinar, conforme definem Hofstetter e Schneuwly (2017), a hipótese teórica é que o saber profissional do professor que ensina matemática seja formado por dois conjuntos de saberes, segundo apropriações de Valente (2019, p. 18): uma matemática a ensinar e uma matemática para ensinar. Usando suas próprias palavras, a primeira "[...] refere-se à matemática como objeto de ensino do professor. $\bigcirc$ que ele tem que ensinar", que se origina do campo disciplinar matemático. Já a segunda, " [...] leva em conta a formação de professores [...] indica o instrumento para esse ensino, uma ferramenta, portanto [...]" (VALENTE, 2019, p. 21), produzida e dinamizada no exercício da profissão docente. Ademais, devemos considerar que em cada tempo histórico elas mostram-se articuladas ao longo do tempo. Isto é, não é possível desconsiderar sua dissociação. Para Valente (2020), a articulação entre este objeto de ensino e esta ferramenta é o que caracteriza teoricamente o saber profissional do professor que ensina matemática num dado tempo histórico.

É válido ressaltar que estamos interessados em investigar os processos de produção e sistematização dos saberes profissionais sobre a aritmética, ou seja, como informações dispersas se transformam em saber e como se tornam inteligíveis e comunicáveis. Para isso, nos valemos das apropriações de Valente (2018) dos estudos de Burke (2016) que entende como cientifização a passagem de um nível sistemático de conhecimentos a fim de propiciar a apropriação por outros sujeitos. Valente (2018) também enuncia etapas para investigação deste processo de sistematização de saberes: recompilação de experiências, análise comparativa dos conhecimentos dos docentes e sistematização e uso dos conhecimentos como saberes.

Refletindo sobre isso, esta investigação nos auxilia na compreensão do processo de cientifização de saberes que se sedimentam e se objetivam. No caso dos saberes docentes, eles são elaborados por meio das experiências dos sujeitos em ação, isto é, pelos professores que ensinam matemática e que realizam suas atividades didático-pedagógicas no cotidiano de suas aulas. Ao longo do tempo, este conhecimento do sujeito somado ao conhecimento subjetivo, incorporado, e, também, às experiências docentes, vão, cada vez mais, se despersonalizando, sistematizando-se, transformando-se em saber. 
saber assim sistematizado torna-se inteligível, podendo circular e ser apropriado em diferentes contextos e experiências. Tem-se, desse modo, para uma dada época, a produção de um saber profissional, característico da profissão de ensinar.

Para a nossa trajetória de pesquisa, entendemos a primeira etapa de recompilação de experiências docentes como o inventário de estudos que abordam os saberes de aritmética pesquisados pelos membros do GHEMAT em diferentes fontes, tais como manuais didáticos, revistas pedagógicas, programas de ensino, publicações que informam o trabalho pedagógico dos professores, focalizando aquelas que abordam os saberes sobre aritmética a partir de vários aspectos, orientações de como ensinar, prescrição de graduação, seleção, e outros temas relacionados a como ensinar. Entendemos que este primeiro levantamento representa um conjunto de conhecimentos sobre o ensino de aritmética.

Essa primeira exploração produziu um conjunto de dissertações e teses contidas no Repositório de Conteúdo Digital (RCD) da Universidade Federal de Santa Catarina (UFSC), que de alguma maneira, trataram da Aritmética no período estudado. Neste levantamento identificamos inicialmente 70 trabalhos ${ }^{2}$. $\bigcirc$ primeiro conjunto foi obtido utilizando o filtro ensino de aritmética. Nessa etapa, a busca se deu na seção intitulada Teses e Dissertações em História da Educação Matemática ${ }^{3}$, do RCD, anteriormente mencionado. Em seguida, mesmo com esse quantitativo enorme, passamos a consultar um a um, buscando eliminar aqueles que não se referiam a nenhum saber matemático em específico. Assim, os trabalhos que abordavam a aritmética sob uma perspectiva geral, foram desconsiderados. Após levantamento desses, passamos a observar os conteúdos que cada um tratava. Ao realizar essa tarefa, constatamos então que dentre os conteúdos mais investigados pelos pesquisadores do GHEMAT estava também o Sistema de Pesos e Medidas/Sistema Métrico Decimal, com um maior número de casos. Com isso, resolvemos priorizá-lo, tratando-o neste estudo.

Ainda sobre essa seleção, em grande medida, foi necessário ler os estudos completos a fim de encontrarmos as informações desejadas a priori, visto que algumas pesquisas não tinham como objetivo central analisar o tema por nós proposto. 
Consideramos que o primeiro levantamento representa um conjunto de conhecimento importante sobre um determinado tempo histórico, de modo que possui potencial para nos auxiliar no planejamento das etapas seguintes de análise, visto que nos informa sobre o que o repositório pode oferecer em termos de elementos para o estudo do saber profissional de aritmética, ou seja, da matemática a ensinar e para ensinar. $\bigcirc$ Grupo reconhece a diferença entre conhecimento e saber. $O$ primeiro é mais ligado à subjetividade, à experiência vivida pelos sujeitos, e o segundo é entendido como produto cultural historicamente institucionalizado resultante de sistematização e organização de determinados conhecimentos como o fim de propiciar a sua comunicação (VALENTE, 2018).

Após esse pré-levantamento, construímos um quadro contendo as informações coletadas como título, tipo (dissertação ou tese), ano, autor, objetivos e conclusões. Conforme o caminhar da pesquisa, o quadro foi acrescido de novos itens. Uma primeira proposta de estudo do quadro foi indicar temas recorrentes, como: manuais, personagens da época, seleção e graduação de conteúdo, métodos etc. Essa percepção de pontos iniciais representou para nós uma primeira leitura de informações, uma etapa inicial rumo à "decanta6 ção ${ }^{5 "}$ de elementos de uma matemática para ensinar aritmética.

Na recompilação dos trabalhos verificamos que, mesmo delimitando por temática - a aritmética para os anos iniciais -, ainda assim, o conjunto de obras era muito extenso. Fomos induzidos a considerar sub-temáticas nesse primeiro conjunto. A nossa decantação revelou a recorrência de saberes relativos à inclusão do sistema métrico na escola e, assim, afunilamos para outro indicativo do quadro: o sistema métrico decimal. Por conta disso, e com esse refinamento, formulamos novamente a nossa questão central de pesquisa: Que elementos do saber profissional do professor dos primeiros anos escolares podem ser caracterizados como um Sistema Métrico Decimal para ensinar?

Em um segundo momento, denominado análise comparativa dos conhecimentos dos docentes, fomos em busca dos consensos entre as experiências apontadas por esses profissionais nos materiais, a fim de produzir "[...] um novo inventário, agora composto pela separação daquelas informações sobre experiências docentes que se mostram convergentes do ponto de vista da orientação para o trabalho do professor" (VALENTE, 2018, p. 381). Ou seja, colocando os trabalhos uns em relação aos outros, buscamos as similaridades 
sobre as orientações postas nos manuais estudados, de modo a identificar o que dizem esses estudos sobre o Sistema Métrico Decimal brasileiro.

Para isso, produzimos um segundo quadro, contendo as obras de autores que tratavam, de alguma maneira, sobre os saberes a e para ensinar SMD. Neste quadro nos interessava verificar como os autores caracterizam a matemática para e a ensinar esse saber.

Cabe aqui mencionar que essas informações foram, impreterivelmente, retiradas dos próprios autores do trabalho e não da fonte primária utilizada. Essa informação é importante e merece ser guardada, haja vista que nossa intenção não foi refazer os passos de uma pesquisa acadêmica de mestrado ou doutorado, mas de analisar o que já havia sido feito sob a lógica de quem a escreveu. Coube-nos, portanto, tomar os resultados da forma como eles foram apresentados nos trabalhos. Prosseguindo, adentramos para a etapa da sistematização, a qual será tratada como considerações finais.

Ao realizar as análises sobre os materiais, organizamos uma seleção de saberes docentes visando apresentar aqueles que foram sistematizados sobre o SMD no período estudado. Dessas sistematizações específicas, analisamos os resultados a partir da etapa anterior, cuja pretensão foi caracterizarmos quais conhecimentos podem ser generalizados e utilizados, ou seja, vistos como saberes profissionais do ensino e da formação de professores que ensinam matemática. Para auxiliar, nos apropriamos do procedimento utilizado por Maciel (2019), que elaborou um rol de questões a fim de organizar as informações fornecidas pelas orientações ao ensino, no nosso caso, o SMD. Partindo das primeiras observações, elaboramos algumas questões: Como, historicamente, o Sistema Métrico Decimal foi implantado no Brasil? Como ele é apresentado? Como é desenvolvida a explicação didático-pedagógica sobre o seu ensino? Qual a graduação sugerida para o seu ensino? $\bigcirc$ que está implícito no texto didático sobre os saberes prévios necessários? Qual a sequência proposta? Como o texto didático trata a generalização de procedimentos? Que tipo de verificação do que foi ensinado consta dos manuais?

$\bigcirc$ corpus final de manuais analisados pelos autores, por ordem cronológica, foi: Compêndio de Arithmética composto para o uso das Escolas Primárias do Brasil (1832), de Cândido Baptista de Oliveira; Elementos de Arithmética (1856), de José Joaquim d'Ávila; Elementos de Aritmética (1866, 5. ed.), de Christiano Benedicto Ottoni; Noções sobre o Systema Métrico Decimal 
(1866), de João Bernardes de Azevedo Coimbra; Éléments d'Aritmétique Théorique et Pratique (década de 1870, 4. ed.), de Etiènne Auguste Tarnier; Ensino d'Arithmetica ou Guia do Calculador (1874), de Candido de Souza Rangel; Arithmética Elementar (1878), de Bernardo Alves Carneiro; Arithmética Elementar (1879), de Miguel Maria Jardim; Explicador de Aritmética (década de 1880, 5. ed.), de Eduardo de Sá Pereira de Castro; Thesouro da Infância ou Novo Manual das Escolas Primárias (1885), de Joaquim M. de Lacerda; Compendio do Systema Métrico Decimal para Uso das Escolas Primárias (1889, 5. ed.), de Manuel Ribeiro de Almeida Junior; Aritmética Elementar Ilustrada (1890, 92. ed.), de Antonio Bandeira Trajano; Cadernos (1891a, 1891b, 1891 c, 1891d), de Ramon Roca Dordal; Arithmetica Primaria (12 ed. 1895), de Antônio Bandeira Trajano; Aritmética Elementar (década de 1910, 4. ed.l, de Antônio Monteiro de Souza; Serie Graduada de Mathematica Elementar (1912, 1915), de René Barreto; Segunda Arithmética (1920, 20 ed.), de José Theodoro de Souza Lobo; Cadernos de Problemas de Arithmética [192?a, 192?b], de Benedicto Maria Tolosa; Aritmética Elementar (2. ed. do Livro I-192?), a 3. ed. do livro II (1921) e a 2. ed. do Livro III (1923), de George Büchler; Noções de Arithmética e do Systema Métrico Decimal (s.d.), 8 de Manoel Olympio Rodrigues da Costa.

\section{Recompilação e análise dos trabalhos analisados}

levantamento realizado nos permitiu arrolar uma quantidade significativa de manuais elegidos pelos diferentes autores das pesquisas, um total, portanto, de 20 impressos escolares.

Dentre esses trabalhos, a tese de Elenice Zuin (2007) foi o estudo que concentrou o maior número de impressos escolares analisados e, por isso, a tomaremos para a complementação e compreensão do processo de efetivação do SMD no Brasil. Além desse trabalho, cabe mencionar a existência do texto escrito por Moreira e Massarini (1997, p. 5), no qual os autores tratam sobre as primeiras iniciativas de introdução desse sistema no Brasil, bem como das "[...] contribuições do pioneiro e principal defensor da adoção desse sistema $[\ldots]^{\prime \prime}$ pelo nosso país, o então deputado Cândido Batista de Oliveira.

trabalho de Zuin (2007) dá destaque à inclusão do conteúdo Sistema Métrico Decimal no Brasil e em Portugal - neste artigo foram 
priorizadas apenas as análises relativas aos manuais brasileiros - lidos a partir da publicação nos livros e manuais didáticos. Para tanto, a autora historiciza alguns elementos que antecederam o movimento pelo ensino de tais saberes. Um desses elementos diz respeito à luta pela substituição do antigo sistema de pesos e medidas, acusado de imprecisão e pouca confiabilidade. Como bem foi ressaltado por Lobo ( 1813 apud ZUIN, 2007, p. 87), um desses entraves era "[...] a falta de exatidão dos padrões no comércio". Ele continua:

Havia dificuldade de se encontrar dois arráteis de ferro ou de latão que tivessem uma perfeita igualdade na sua massa - ainda que tivessem sido fabricados na mesma época e fossem expostos às mesmas condições ambientais (LOBO, 1813 apud ZUIN, 2007, p. 87).

Essas e outras dificuldades são também apresentadas por Moreira e Massarini (1997). A ideia de adoção de um sistema métrico uniforme em seus padrões ganhou impulso com a abertura dos portos brasileiros a outras nações e com a Independência do Brasil, onde viu-se "[...] a necessidade do novo estado ditar as normas comerciais e arrecadar impostos" IMOREIRA; MASSARINI, 1997, p. 5). Neste contexto, a adoção do sistema de pesos e medidas francês parecia dar conta das dificuldades sinalizadas, entretanto, como todas as tentativas de mudanças em práticas sociais, a adoção do novo sistema enfrentou muitas dificuldades e a escola foi uma das instituições importantes para a efetivação dessas mudanças.

No Brasil, a Lei imperial de 1862, Lei n 1.157 , de 26 de junho, determinava a substituição no prazo de 10 anos, em todas as escolas primárias, do sistema de pesos e medidas pelo sistema métrico francês (BRASIL, 1862). A partir dos referenciais por nós adotados, a saber, da História Cultural, como também dos conceitos de cultura escolar e de história das disciplinas escolares, as mudanças na vida social não se dão por simples decreto. Isso pode ser observado pelo longo e tenso processo percorrido para o assentamento do SMD no sistema escolar e na própria prática social. A escolha de certos conteúdos e sua incorporação em currículos institucionalizados é algo que demanda tempo (FORQUIN, 1992).

Isso, de fato, pode ser observado pelo contexto de tentativas frustradas de implantação do SMD no Brasil. De acordo com Moreira e Massarini (1997), a primeira ocorreu em 1830, no entanto não foi adiante. Em 1832, Cândido 
Batista publica seu livro intitulado Compêndio de Aritmética - Composto para Uso das Escolas Primárias do Brasil, numa tentativa de dar visibilidade à sua escolha. Mesmo com essa obra já em circulação, entre 1834 e 1836, mais um projeto de reforma foi barrado no Senado. Já nos anos de 1857 e 1861 , Cândido Batista mudou de estratégia e passou a publicar na Revista Brazileira dirigida e criada por ele, noções de metrologia em que defendia o uso do sistema métrico decimal. Somente em 1862 é que há a aceitação do sistema métrico (MOREIRA; MASSARINI, 1997).

No Brasil oitocentista, questões culturais, ou mesmo questões de utilidade social, dificultavam a incorporação do sistema decimal de pesos e medidas na escola; mesmo após a homologação do referido decreto, havia diferenças de metodologia, de recursos etc., para a abordagem do conteúdo (ZUIN, 2007). Corroborando com Forquin (1992), acrescentamos que a seleção cultural feita pela escola é historicamente determinada pelas condições sociais, políticas e ideológicas.

Em seguida, passamos a destacar as análises que foram efetuadas pelos pesquisadores do GHEMAT, quanto ao tratamento das fontes escolhidas.

\section{Sistematização: o SMD a e para ensinar: algumas aproximações}

A partir do que foi efetuado e analisado anteriormente, buscamos evidenciar aquilo que foi "decantado" ao longo do tempo, desde o ano de 1832 até a década de 1920. A referência à 1832 se deve ao ano de publicação do primeiro livro encontrado, intitulado Compêndio de Arithmética - Composto para o Uso das Escolas Primárias do Brasil, do autor Cândido Batista de Oliveira (1832), o qual trazia informações sobre o sistema métrico francês (ZUIN, 2007; MOREIRA; MASSARINI, 1997). Levando em conta critérios como apresentação, graduação, exercícios, definições e aplicação, foi possível identificar alguns traços comuns a estes manuais, levando-nos a uma decantação daquilo que perdurou e que pode ser visto como saberes a e para ensinar SMD.

Observamos inicialmente certa recorrência à uma apresentação de diferentes tabelas para conversão. A difusão de tabelas comparativas era, segundo Moreira e Massarini (1997), um dos itens presentes na Lei n 1157 , de 26 de junho de 1862. Em outras palavras, até pelo menos meados da década 
de 1870, essas tabelas atendiam a uma demanda do governo para facilitar as conversões das medidas de um sistema para o outro (OTTONI, 1866 apud ZUIN, 2007), de modo que eram incorporadas aos manuais escolares, muitas vezes, sem contemplar exercícios de transformação de unidades (OLIVEIRA, 1832; ÁVILA, 1856 apud ZUIN, 2007), deixando de lado a pretensão de tratamento de problemas resolvidos. Ao que tudo indica, essa tendência justifica-se pelo fato de o sistema de pesos e medidas, antigo ou decimal, ser visto como uma prática social, importante mecanismo para as lides do comércio local daquela época.

Outra constatação importante diz respeito ao lugar onde aparecem as primeiras discussões sobre o SMD nos manuais analisados. Pelo que foi possível identificar, em pelo menos três deles (OLIVEIRA, 1832; OTTONI, 1866; CARNEIRO, 1878 apud ZUIN, 2007) o assunto era tratado de forma isolada, em caráter de apêndices. Sobre isso, Zuin (2007) afirma que o fato de esse conteúdo constar apenas do apêndice de uma obra pode indicar certa dificuldade no trato com seu trabalho e na aceitação pelas escolas, o que reforça ainda mais a nossa hipótese de que esse conteúdo inicia seu processo de escolarização desvinculado da escola, relegado a segundo plano, apresentando pouca importância para os trabalhos escolares. Ou seja, sua aceitação ainda estava em vias de efetivação. Mas observaremos que esse cenário sofrerá modificações. O SMD ganhará status de saber escolar.

Muitos manuais passaram a reivindicar um caráter prático e utilitário do conteúdo ICOIMBRA, 1866 apud ZUIN, 2007; TARNIER, 1870 apud SOUZA, 2010; RANGEL, 1874 apud ZUIN, 2007; JARDIM, 1879 apud FEITOSA, 2018; ALMEIDA JUNIOR, 1889 apud ZUIN, 2007; SOUZA, 1890 apud SOUZA, 2010; DORDAL, 1891 apud TRINDADE, 2018; TOLOSA, 1921 apud TRINDADE, 2018; BÜCHLER, 192? apud TRINDADE, 2018). Um exemplo emblemático disso é o caso do manual endereçado ao público "Calculador" (RANGEL, 1874 apud ZUIN, 2007), dando a entender, mais uma vez, tratar-se de um conteúdo desvinculado da escola primária, haja vista servir quase que unicamente aos trabalhos comerciais. Todavia, essa definição de caráter prático, apontada acima, vai mudando com o tempo, como veremos mais adiante.

A estrutura inicial dos manuais com poucos exercícios (resolvidos), poucas figuras/gravuras, começa a ruir a partir da década de 60 dos Oitocentos, quando já se percebe um movimento de explorar as tabelas comparativas a partir de exemplos de transformação das medidas antigas para as novas 
(COSTA, s/d; OTTONI, 1866; LACERDA, 1885 apud ZUIN, 2007). Observa-se que os autores dos manuais analisados começam a se preocupar com a reorganização em função da progressão de dificuldades, com a sinalização do passo a passo por meio de exemplos e exercícios resolvidos (COIMBRA, 1866 apud ZUIN, 2007; CARNEIRO, 1878 apud ZUIN, 2007; TARNIER, 1870 apud SOUZA, 2010; JARDIM, 1879 apud FEITOSA, 2018; ALMEIDA JUNIOR, 1889 apud ZUIN, 2007; TRAJANO, 1890 apud SOUZA, 2010; apud GOUVEIA, 2017; SOUZA, 1890 apud SOUZA, 2010; DORDAL, 1891 apud TRINDADE, 2018; BARRETO, 1912, 1915 apud TRINDADE, 2018; LOBO, 1920 apud GOUVEIA, 2017; BÜCHLER, 192? apud TRINDADE, 2018). Seguiam uma lógica baseada na teoria e na abstração, isto é, fazendo apelo às regras, definições e exemplos para praticar os conceitos. Novos rumos trariam posturas diferentes.

A partir da segunda metade do século XIX, nota-se a presença da abordagem do uso da regra de três simples e composta (COSTA, s/d apud ZUIN, 2007; CARNEIRO, 1878 apud ZUIN, 2007; LACERDA, 1885 apud ZUIN, 2007) para tratar o SMD, embora depois isso comece a ser menos enfatizado. Ainda sobre o conteúdo Regra de Três Simples ou Composta, Zuin (2007) afirma que Carneiro (1878) optou por não usar regra de três nos problemas por 12 ele apresentados, por considerar um conhecimento impróprio para crianças, apelando, assim, para os "[...] methodos directos, intuitivos" (CARNEIRO, 1878 apud ZUIN, 2007, p. 246). Sobre o uso feito por Lacerda (1 885), Zuin (2007) comenta que o processo utilizado por ele, para abordar a regra de três composta, era difícil para as crianças do ensino primário, e que ao ser resolvido aritmeticamente, tornava-se mais longa e de natureza pouco acessível para elas, julgando-a desnecessária para aquele nível de ensino.

No final do século XIX, um manual que parece romper com os anteriores é o de Almeida Junior ( 1889 apud ZUIN, 2007). Assemelhando-se aos demais nos quesitos caráter de utilidade prática, exposição teórica e detaIhada, diferenciava-se deles pelo quantitativo de figuras e ilustrações que continha, mas, sobretudo, pela defesa de fazer com que os alunos conhecessem primeiro as noções sobre SMD para depois estudar frações ordinárias ou que o SMD e frações decimais fossem vistos juntos, como pode-se observar no Quadro 1, a seguir. Nos manuais anteriores havia a premissa de que para estudar SMD eram necessários alguns pré-requisitos, tais como frações decimais e frações ordinárias. Pelo visto esse era um imperativo forte para a época e um 
saber para ensinar que deveria fazer parte dos saberes profissionais do professor que ensinava Matemática.

De um modo geral, observamos que os manuais se organizaram em uma lógica na qual o SMD era abordado, na grande maioria das vezes, após o ensino das frações decimais (ou seja, FD $\rightarrow$ SMD) (ÁVILA, 1856; COIMBRA, 1866; RANGEL, 1874; CARNEIRO, 1878 apud ZUIN, 2007; JARDIM, 1879 apud FEITOSA, 2018; CASTRO, 1880 apud SOUZA, 2010; LACERDA, 1885 apud ZUIN, 2007; SOUZA, 1890 apud SOUZA, 20 10; TRAJANO, 1890; LOBO, 1920 apud GOUVEIA, 2017). Como se vê, essa foi a representação mais importante deste período. A escolha deste pré-requisito não é por acaso. Sua abordagem antes do SMD se justifica pelo auxílio junto ao sistema de medidas, um meio de viabilizar esse estudo, normalmente de base decimal. Essa justificativa sinaliza para nós a existência de um ensino progressivo, baseado num encadeamento dos conteúdos, o qual considera o ensino e as necessidades cotidianas, e que pode se diferenciar de uma perspectiva que respeite a organização lógica interna desses, devedora de uma disciplina, a Matemática.

Oestudo das frações ordinárias aparece nos seguintes autores: Costa (s/d apud ZUIN, 2017); Avila (1856 apud ZUIN, 2007); Rangel (1874 apud ZUIN, 2007); Carneiro ( 1878 apud ZUIN, 2007); Jardim ( 1879 apud FEITOSA, 2018 ); Castro (1880 apud SOUZA, 2010); Souza (1890 apud SOUZA, 2010); Trajano (1890 apud GOUVEIA, 2017); Büchler (1923 apud TRINDADE, 2018) visto antes de SMD (FO $\rightarrow$ SMD). Cabe ainda destacar que nenhum manual analisado ousou tratar as frações decimais depois do SMD (SMD $\rightarrow$ FD), embora tenhamos identificado o estudo das frações ordinárias depois do SMD $(\mathrm{SMD} \rightarrow \mathrm{FO})$, como foi o caso de Almeida Junior ( 1889 apud ZUIN, 2007), Dordal (1891 apud TRINDADE, 2018) e Lobo (1920 apud GOUVEIA, 2017). 


\section{Quadro 1}

Ordenação de conteúdos para o ensino de SMD

\begin{tabular}{|c|c|c|c|c|c|}
\hline $\mathrm{N}^{\circ}$. & $\begin{array}{c}\text { Autor e } \\
\text { ano }\end{array}$ & Sequenciamento & $N^{\circ}$. & Autor e ano & Sequenciamento \\
\hline 1 & $\begin{array}{l}\text { Oliveira } \\
\text { (1832) }\end{array}$ & Apêndice & 11 & $\begin{array}{l}\text { A I m e i d a } \\
\text { Junior (1 889) }\end{array}$ & $\begin{array}{c}S M D \rightarrow F O \\
S M D+F D .\end{array}$ \\
\hline 2 & 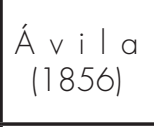 & $\mathrm{FR} \rightarrow \mathrm{FD} \rightarrow \mathrm{SMD}$ & 12 & $\begin{array}{c}\text { Trajano (dé- } \\
\text { cada de } \\
1890 \text { ) }\end{array}$ & $\mathrm{FO}, \mathrm{FD} \rightarrow \mathrm{SMD}$ \\
\hline 3 & $\begin{array}{l}\text { Ottoni } \\
(1866)\end{array}$ & Apêndice & 13 & $\begin{array}{l}\text { Souza (déca- } \\
\text { da de } 1890 \text { ) }\end{array}$ & $\mathrm{FO} \rightarrow \mathrm{FD} \rightarrow \mathrm{SMD}$ \\
\hline 4 & $\begin{array}{c}\text { Coimbra } \\
(1866)\end{array}$ & $\mathrm{FD} \rightarrow \mathrm{SMD}$ & 14 & $\begin{array}{c}\text { Dor d a l } \\
(1891)\end{array}$ & $\mathrm{DO} \rightarrow \mathrm{SM} \rightarrow \mathrm{MD} \rightarrow \mathrm{FR}$. \\
\hline 5 & $\begin{array}{l}\text { Tarnier } \\
\text { (década } \\
\text { de 1870) }\end{array}$ & ND $\rightarrow$ Frações & 15 & $\begin{array}{c}\text { Barreto } \\
(1912 \\
1915)\end{array}$ & $\begin{array}{l}\text { O autor trabalha } \\
\text { com lições. Não há } \\
\text { um capítulo espe- } \\
\text { cífico denominado } \\
\text { SMD. }\end{array}$ \\
\hline 6 & \begin{tabular}{|l} 
Rangel \\
$(1874)$
\end{tabular} & $\begin{array}{c}\mathrm{FR} \rightarrow \mathrm{ND} \rightarrow \mathrm{NC} \rightarrow \mathrm{SPMA} \\
(\mathrm{SMD})\end{array}$ & 16 & Lobo (1920) & $\mathrm{FD} \rightarrow \mathrm{SMF} \rightarrow \mathrm{FO}$. \\
\hline 7 & $\begin{array}{c}\text { Carneiro } \\
(1878)\end{array}$ & $\mathrm{FR} \rightarrow \mathrm{FD} \rightarrow \mathrm{SMD}$ & 17 & $\begin{array}{c}\text { To } \mid \circ \text { s a } \\
(1921) \\
\end{array}$ & $\begin{array}{c}\text { Não foi possível } \\
\text { identificar. }\end{array}$ \\
\hline 8 & $\begin{array}{l}\text { J a rd i m } \\
\text { (1879) }\end{array}$ & $\mathrm{FO} \rightarrow \mathrm{FD} \rightarrow \mathrm{SMD}$ & 18 & $\begin{array}{c}\text { B ü c h l e r } \\
\text { (192?) }\end{array}$ & $\begin{array}{l}\text { autor trabalha } \\
\text { com assuntos. Não } \\
\text { há um capítulo } \\
\text { específico denomi- } \\
\text { nado SMD. Mas no } \\
\text { manual de } 1923 \text {, } \\
\text { tem-se: } \\
\text { MT } \rightarrow \text { FD } \rightarrow \text { SA } \rightarrow \mathrm{V} \rightarrow P \text {. }\end{array}$ \\
\hline 9 & $\begin{array}{l}\text { Castro } \\
\text { (década } \\
\text { de 1880) }\end{array}$ & $\mathrm{FO} \rightarrow \mathrm{FD} \rightarrow \mathrm{SMD}$ & 19 & Costa (s.d.) & $\mathrm{FO} \rightarrow \mathrm{ME} \rightarrow \mathrm{NC} \rightarrow \mathrm{RP}$. \\
\hline 10 & \begin{tabular}{|c|} 
Lacerda \\
$(1885)$
\end{tabular} & $\mathrm{PMA} \rightarrow \mathrm{ND} \rightarrow \mathrm{NC} \rightarrow \mathrm{NSLM}$ & 20 & & \\
\hline
\end{tabular}

Fonte: elaboração própria. 


\section{Legenda}

\begin{tabular}{|l|l|}
\hline FD - Frações Decimais & FO - Frações Ordinárias \\
\hline SM/D - Sistema Métrico/Decimal & PMA - Pesos e Medidas Antigos \\
\hline ND - Números Decimais & $\begin{array}{l}\text { NSLM - Novo Sistema Legal de } \\
\text { Medidas }\end{array}$ \\
\hline NC - Números Complexos & DO - Decimais e Operações \\
\hline $\begin{array}{l}\text { SPMA - Sistema de Pesos e Medidas } \\
\text { Atuais }\end{array}$ & MD - Medidas \\
\hline FR - Frações & SMF - Sistema métrico francês \\
\hline SA - Superfícies ou Áreas & MT - Metro \\
\hline V - Volumes & P - Pesos \\
\hline ME - Metrologia & RP - Razão e Proporção \\
\hline
\end{tabular}

Fonte: elaboração própria.

Podemos ainda verificar observando o Quadro 1 que a escolarização do SMD induziu uma mobilização do ensino de frações, sejam elas decimais ou ordinárias.

A utilização de ilustração, de desenhos de instrumentos, é outra característica que vai ganhando espaço em alguns manuais. Geralmente, as ilustrações representavam desenhos de instrumentos de pesos e medidas, moeda, ou para complementar explicações (COIMBRA, 1866 apud ZUIN, 2007). Já para o final do período, percebemos que as ilustrações começam a fazer parte da complementação da teoria, remetendo ao texto explicativo, contribuindo para motivar os alunos no percurso do simples ao complexo, do que se sabe para o que se ignora, como se pode observar com a publicação de Trajano (1890) e de autores como Jardim (1 879 apud FEITOSA, 2018), Castro ( 1880 apud SOUZA, 2010), Almeida Junior (1 889 apud ZUIN, 2007), Barreto (1912, 1915 apud TRINDADE, 2018), Lobo (1920 apud GOUVEIA, 2017) e Büchler (192? apud TRINDADE, 2018).

Quando refletimos acerca da integração dos conteúdos do SMD com a Geometria, podemos pensar que no início da escolarização desse saber não houve, na grande maioria dos manuais estudados, interações com a Geometria. Observamos em relação a sua ordenação diferentes movimentos para implementação do SMD ao ensino, contudo sem grandes diferenças na 
abordagem e metodologia: introdução do conteúdo com a apresentação de aspectos históricos e a utilização de tabelas para operar as transformações de medidas. Com o decorrer da implementação do SMD, alguns autores se arriscam na proposição de outras maneiras. Destacamos Jardim (1879 apud FEITOSA, 2018) que procura estimular a interação do SMD com a Geometria fazendo uso de expressões "exemplos para praticar". No caso do SMD, esses exercícios englobavam cálculo de áreas e volumes. Souza (2010), observa que Trajano tratava os exercícios e problemas de cálculo de área e volume mantendo as grandezas sempre na mesma unidade, sem necessidade de transformação (SOUZA, 2010). Dordal (1891 apud TRINDADE, 2018) também apresentava problemas de cálculos de áreas e volumes acompanhados de transformações de medidas em um mesmo problema.

Na passagem do século XIX para o século XX, alguns manuais trazem explicitamente a mobilização de um caráter prático com estreitas ligações com o cotidiano do aluno (DORDAL, 1891; BARRETO, 1912, 1915; TOLOSA, 1921 ; BÜCHLER, 192?). Esse conjunto específico de manuais foi analisado por Trindade (2018). O estudo dessa autora buscou evidenciar as mobilizações e as finalidades do ensino das medidas em manuais de aritmética. Em razão 16 de seu ensino a partir das, sobre e com as medidas, o SMD servia para ilustrar situações da vida cotidiana. Essa evidência de um caráter prático identificado pela autora fazia eco em exercícios e problemas com "linguagem da vida prática", de "distintas contextualizações com a vida" (TRINDADE, 2018, p. 124), situações que levavam o aluno ao ato de medir, ao ato de fazer medições etc. Nesse ínterim, Trindade (2018) ainda destaca que a apropriação prática de Dordal (1891) e Barreto (1912, 1915) era diferente. E explica que na proposta do segundo autor, além de conhecer as unidades de medidas, era necessário que o aluno soubesse manusear os instrumentos de medida, assim como representasse em escrita as suas unidades, ou seja, efetuassem os cálculos mediante a medição dos objetos.

Outro ponto a ressaltar refere-se à tentativa de alinhar o saber calcular com o saber medir, empregado por alguns autores (COSTA, s/d; OTTONI, 1866; LACERDA, 1885 apud ZUIN, 2007) que enfatizam transformações de medidas. Acrescentamos que Antonio Monteiro de Souza 11910 apud SOUZA, $2010)$, diferentemente dos demais analisados, utilizou figuras geométricas para ensinar a transição das diferentes grandezas do sistema métrico decimal que podem ser apresentadas como medidas lineares e medidas quadradas. 
De outra parte, importa apresentar o que poderia se caracterizar como concepções/definições a respeito do SMD, as quais, ao que parece, não gozavam muito de uma teorização. As "definições", ou sentidos atribuídos para a apresentação do SMD, apareciam com asserções que discriminavam a natureza das medidas contempladas nesse sistema, a saber:

$1^{a}$ de tempo ou duração, - $2^{a}$ angular, $-3^{a}$ de extensão, $-4^{a}$ de peso - $5^{a}$ de valor; as quaes, juntamente com as unidades que se formão de múltiplos ou submúltiplos respectivos, constituem diferentes systemas (OLIVEIRA, 1832 apud ZUIN, 2007, p. 211 ).

Ou de uma forma mais generalista: "Define-se systema de pezos e medidas ao complexo de todos os pezos e medidas adoptados numa nação [...]" (COIMBRA, 1866 apud ZUIN, 2007, p. 234). Havia também os sentidos relativos à medida dos meridianos terrestres, sendo o metro a milionésima parte do meridiano (ZUIN, 2007). Ou ainda: "[...] é o systema de pesos e medidas que tem por base o metro" (SOUZA, 1890 apud SOUZA, 2010). E ainda aquela que em consonância com essa, ampliava o sentido, tangenciando com o próprio sentido da ciência matemática:

O conjunto de meios de medição indirecta constitue uma sciencia vastíssima, denominada Mathematica (da qual faz parte a Arithmetical; e para a medição directa emprega-se um certo número de unidades, cujo complexo forma um systema metrológico ICARNEIRO, 1878 apud ZUIN, 2007, p. 245).

Assim, podemos inferir sobre alguns saberes que esses autores de manuais buscaram sistematizar. $\bigcirc$ Sistema Métrico Decimal constituía um novo saber em substituição aos sistemas antigos, utilizados antes da Lei que normatizava o Sistema Métrico Francês no Brasil, de maneira que o uso de tabelas foi recorrente nos primeiros manuais, objetivando ensinar a transformar medidas. No entanto, essa forma de ensino foi desaparecendo em razão da sua consolidação como um saber específico, bem como da sua utilização nas relações cotidianas - comércio. Em grande medida o uso de tabelas para ensinar a transformar medidas era parte de um dos saberes que esses manuais tentaram sistematizar.

Verificamos que os manuais analisados fornecem elementos e variações para caracterizarmos um sistema métrico decimal a ensinar e para 
ensinar. Esse movimento pode ser lido primeiro com a introdução desse saber, ainda não escolarizado nem objetivado, apenas como apêndice, sem garantir um "espaço" em uma matéria específica (aritmética ou geometria) e tampouco em programas de ensino; depois, com a escolarização do SMD, inova-se, inserindo-o como conteúdo da aritmética, abordando-o com problemas de transformação de medidas, apelando para problemas práticos, exercícios resolvidos etc.; posteriormente, há uma produção de manuais voltados para uma matemática intuitiva para ensinar com e a partir do Sistema Métrico Decimal. Os problemas agora focavam o SMD utilizando uma linguagem cotidiana, próxima à realidade dos alunos e com o uso de instrumentos de medida (balança, fita métrica, régua, relógio, recipiente equivalente a um litro etc.). De maneira que o ensino do SMD se desloca de uma ênfase de apenas saber calcular, para contemplar também o saber aplicar, o ter domínio da utilização dos instrumentos. Nesse período importa destacar a singularidade das proposições de Barreto (1915 apud TRINDADE, 2018) no que diz respeito a um método conforme um modelo espiral para abordar o saber SMD. Em outras palavras, significava dizer que nesse modelo os conteúdos eram retomados segundo uma progressão de nível, com retorno a uma dada lição sempre num nível mais 18 avançado, mesclando o antigo conteúdo com o novo. Da leitura do trabalho de Trindade (2018), pudemos observar também que o SMD era apresentado ora como instrumento para outros conteúdos ora como conteúdo principal. Portanto, iniciava-se a disseminação de manuais que tomaram o ensino prático do Sistema Métrico Decimal, mas com orientações para ensinar aritmética e geometria. Em grande medida saber medir era saber calcular.

Os saberes para ensinar o SMD se alteraram ao longo do tempo. Deixaram de ser pautados numa abordagem na qual bastava ao professor saber ensinar as notações correspondentes, utilizar os apêndices com as respectivas tabelas para as conversões, e passaram a ser pensados a partir da necessidade de um ensino que atuaria em consonância com problemas práticos, contextualizados, exigindo do profissional saber utilizar instrumentos, ilustrações e também aplicar esses saberes na vida cotidiana; há uma passagem de uma ênfase abstrata para uma concreta, caracterizando, assim, um SMD intuitivo, prático. Dessa forma, altera-se também o SMD como um saber a ensinar, ou seja, há uma mudança na sua concepção, tendo em vista sua transformação ao longo do tempo via associação ao ensino de Geometria, bem como às próprias operações aritméticas e ao auxílio a outros conteúdos etc. 


\section{Notas}

$1 \quad \bigcirc$ primeiro é denominado A constituição dos saberes elementares matemáticos: a aritmética, a geometria e o desenho no curso primário em perspectiva histórico-comparativa, 1890-1970, e o outro mais recente (período de vigência de 2017 a 2022), denominado A matemática na formação de professores e no ensino: processos e dinâmicas de produção de um saber profissional, 1890-1990 (VALENTE; BERTINI; PINTO; MORAIS, 2017).

2 A consulta foi realizada em: 10 jun. 2020.

3 Disponível ao acessar o link: https://repositorio.ufsc.br/handle/123456789/1791.

4 Como conceito de número, operações fundamentais, tabuada, prova dos noves, multiplicação para ensinar, cálculo oral para ensinar etc.

5 A busca de padrões de saberes para a formação de professores que ensinam matemática resulta de processos de decantação. O resultado dessa decantação é, para um dado tempo, o saber profissional do professor (VALENTE, 2020).

\section{Referências}

BRASIL. Lei Imperial $\mathbf{n}^{\circ} \mathbf{1} .157$, de 26 de junho de 1862. Substitue em todo o Imperio $\circ$ actual systema de pesos e medidas pelo systema metrico francez. Rio de Janeiro, 12 ago. 1862.

BURKE, Peter. O que é história do conhecimento? Tradução Cláudia Freire. São Paulo: Editora UNESP, 2016.

CHARTIER, Roger. História das disciplinas escolares: reflexões sobre um campo de pesquisa.

Teoria \& Educação, Porto Alegre, v. 2, p. 177-229, 1990.

FEITOSA, Rosiane Morais dos Santos. A aritmética na escola primária do Espírito Santo na década de 1870: percepções a partir da obra de Miguel Maria Jardim. 2018. $160 f$. Dissertação (Mestrado em Ensino na Educação Básica) - Programa de Pós-Graduação em Ensino na Educação Básica, Universidade Federal do Espírito Santo, São Mateus, 2018. Disponível em: http://repositorio.ufes.br/bitstream/10/10950/1/tese_12722_88\%20-\%20Rosiane\%20Morais\%20dos\%20Santos\%2OFeitosa.pdf. Acesso em: 5 nov. 2020.

FORQUIN, Jean Claude. Saberes escolares, imperativos didáticos e dinâmicas sociais. Teoria \& Educação, Porto Alegre, v. 5, p. 28-49, 1992.

GOUVEIA, Relicler Pardim. Mêtre, litre, gramme... grandezas e unidades de medidas na cultura matemática escolar. 2017. 226f. Dissertação (Mestrado em Educação Matemática) - Programa de Pós-Graduação em Educação Matemática, Universidade Federal de Mato Grosso do Sul, Campo Grande, 2017. Disponível em: https://repositorio.ufsc.br/handle/123456789/189629. Acesso em: 25 jul. 2020. 
Que aritmética para ensinar sistema métrico decimal? Saberes profissionais para o seu ensino

HOFSTETTER, Rita; SCHNEUWLY, Bernard. Penetrar na verdade da escola para ter elementos concretos de sua avaliação: a irresistível institucionalização do expert em educação (século XIX e XX). In: HOFSTETTER, Rita; VALENTE, Wagner Rodrigues (org.). Saberes em (trans)formação: tema central da formação de professores. São Paulo: Editora Livraria da Física, 2017.

MACIEL, Viviane Barros. Elementos do saber profissional do professor que ensina matemática: uma aritmética para ensinar nos manuais pedagógicos (1880-1920). 2019. 312 f. Tese (Doutorado em) - Programa de Pós-Graduação Educação e Saúde na Infância e na Adolescência, Universidade Federal de São Paulo, 2019. Disponível em: https://repositorio.ufsc.br/handle/123456789/199390. Acesso em: 24 ago. 2020.

MOREIRA, Ildeu de Castro; MASSARINI, Luisa. Cândido Batista de Oliveira e a implantação do sistema métrico decimal no Brasil. Revista da Sociedade Brasileira de História da Ciência, v. 18, p. 3-16, 1997.

SOUZA, Rosa Fátima de. Alicerces da pátria: história da escola primária no estado de São Paulo (1 890-1976). Campinas: Mercado de Letras, 2009.

SOUZA, Tarcísio luiz Leão e. Elementos históricos da educação matemática no Amazonas: livros didáticos para ensino primário no período de 1870 a 1910. 2010. 20 160f. Dissertação (Mestrado em Educação Matemática) - Programa de Pós-Graduação em Educação Matemática, Universidade Federal do Mato Grosso do Sul, Campo Grande, 2010. Disponível em: https://repositorio.ufsc.br/handle/123456789/126167. Acesso em: 25 jul. 2020.

TRINDADE, Deoclecia de Andrade. As artes de medir: saberes matemáticos no ensino primário de São Paulo, 1890-1950. 2018, 190f. Tese (Doutorado em) -Programa de PósGraduação Educação e Saúde na Infância e na Adolescência, Universidade Federal de São Paulo, 2018. Disponível em: https://repositorio.ufsc.br/handle/123456789/192879. Acesso em: 24 ago. 2020.

VALENTE, Wagner Rodrigues. Processos de investigação histórica da constituição do saber profissional do professor que ensina matemática. Acta Scientiae, Canoas, v. 20, n. 3, p. 377-385, maio/jun. 2018.

VALENTE, Wagner Rodrigues. Que matemática para formar o futuro professor? História do saber profissional do professor que ensina matemática. Revista Exitus, Santarém, v. 9, n. 2, p. 15-25, abr./jun. 2019.

VALENTE, Wagner Rodrigues. Teacher training and historical studies on professional knowledge: mathematics to teach and mathematics for teaching. Pedagogical Research, v. 5, n. 3, 2020. 
Disponível em: hitps://repositorio.ufsc.br/bitstream/handle/123456789/208701/ Teacher\%20Training\%20and\%20Historical\%20Studies\%20on\%2OProfessional\%20 Knowledge\%20Mathematics\%20to\%20Teach\%20and\%20Mathematics\%20for\%20 Teaching. pdf? sequence=1 \&isAllowed=y. Acesso em: 18 jun. 2020.

VALENTE, Wagner Rodrigues; BERTINI, Luciane de Fátima; PINTO, Neuza Bertoni; MORAIS, Rosilda dos Santos A matemática na formação de professores e no ensino: processos e dinâmicas de produção de um saber profissional, 1890-1990. São Paulo: FAPESP, 2017. Disponível em: https://tinyurl.com/y8z732yp. Acesso em: 23 jun. 2020.

VIDAL, Diana. Grupos escolares: cultura escolar primária e escolarização da infância no Brasil "1893-1971". Campinas: Mercado de Letras, 2006.

ZUIN, Elenice. Por uma nova arithmetica: o sistema métrico decimal como um saber escolar em Portugal e no Brasil oitocentista. 2007, 31 8f. Tese (Doutorado em Educação Matemática) - Programa de Educação Matemática, Pontifícia Universidade Católica de São Paulo, 2007. Disponível em: hitps://repositorio.ufsc.br/handle/123456789/177674. Acesso em: 25 nov. 2019.

Marcos Dr. Denilson Guimarães

Universidade Federal do Maranhão (Brasil)

Professor Visitante do Programa de Pós-Graduação em Ensino de Ciências e Matemática Grupo de Pesquisa de História da Educação Matemática (GHEMAT) E-mail: marcos.denilson@ufma.br Orcid id: https: / / orcid.org/0000-0002-9967-4624 
Profa. Dra. Martha Raíssa lane Santana da Silva Grupo de Pesquisa de História da Educação Matemática (GHEMAT) E-mail: martharaissa@hotmail.com Orcid id: https:/ / orcid.org/0000-0002-18 1 8-0957

Profa. Dra. Denise Medina França Universidade do Estado do Rio de Janeiro (Brasil) Professora do Programa de Pós-Graduação em Educação Grupo de Pesquisa de História da Educação Matemática (GHEMAT) E-mail: denisemedinafranca@gmail.com Orcid id: https: / / orcid.org/0000-0002-1649-5816 